\title{
IONOSPHERIC DISTURBANCES OVER EAST ASIA DURING INTENSE DECEMBER MAGNETIC STORMS OF 2006 AND 2015: SIMILARITIES AND DIFFERENCES
}

\author{
N.A. Zolotukhina \\ Institute of Solar-Terrestrial Physics SB RAS, \\ Irkutsk, Russia, zolot@iszf.irk.ru

\section{V.I. Kurkin} \\ Institute of Solar-Terrestrial Physics SB RAS, \\ Irkutsk, Russia, kurkin@iszf.irk.ru
}

\author{
N.M. Polekh \\ Institute of Solar-Terrestrial Physics SB RAS, \\ Irkutsk,Russia,polekh@iszf.irk.ru
}

\begin{abstract}
Using data from ionosondes, located in East Asia, and total electron content maps, we have made a comparative analysis of ionospheric disturbances associated with the intense geomagnetic storms of December 14-16, 2006 and December 19-22, 2015. These storms had almost equal peak intensities $\left(D s t_{\min }=-162\right.$ and $\left.-155 \mathrm{nT}\right)$, but different durations of the main phases (2.5 and $19 \mathrm{hr}$ ). At the beginning of both the storms, the region under study was located in the vicinity of the midnight meridian. Ionospheric responses to magnetic storms differed in: i) an increase in the F2-layer critical frequency at subauroral latitudes, caused by an increase in auroral precipitation, during the initial phase of the former storm and the absence of this effect in the latter; (ii) a sharp drop in the critical frequency in the evening hours of the main phase of the latter storm, caused by a shift of the main ionospheric trough to lower latitudes, and the absence of this effect during the former storm; (iii) generation of a short-term
\end{abstract}

positive disturbance observed at subauroral latitudes only in the early recovery phase of the former storm after the negative ionospheric disturbance. During both the storms at middle latitudes there were positive disturbances and wave-like fluctuations of the critical frequency which increased in the vicinity of the dawn meridian. The main causes of the differences between the ionospheric storms are shown to be the differences between the initial conditions of the magnetosphereionosphere system and durations of the main phases of magnetic storms.

Keywords: severe magnetic storms, interplanetary drivers, winter ionospheric storm effects.

\section{INTRODUCTION}

The response of the magnetosphere-ionosphere system to interplanetary inhomogeneities manifests itself in extreme cases as geomagnetic storms and their attendant ionospheric disturbances called ionospheric storms [Bryunelli,Namgaladze, 1988]. The spatio-temporal dynamics of magnetospheric-ionospheric storms depends on various external and internal factors. The main external factors are considered to be the type and power of interplanetary drivers of storms, as well as the time during which they affect Earth's magnetosphere. The internal factors include the initial state of the magnetosphere-ionosphere system, season, universal time of storm onset (UT), geographic and geomagnetic position of an observation point, its local time (LT) at the beginning of the storm, etc. [Buonsanto, 1999; Goodman, 2005; Sharma et al., 2005; Mendillo, 2006; Kalita et al., 2016].

Geoeffectiveness of interplanetary structures is estimated from solar wind density $\left(N_{\mathrm{sw}}\right)$ and velocity $\left(V_{\mathrm{sw}}\right)$, azimuthal $\left(B_{\mathrm{y}}\right)$ and vertical $\left(B_{\mathrm{z}}\right)$ components of the interplanetary magnetic field (IMF) [Lee et al., 2004; Clauer et al., 2006; Gonzalez et al.,2011; Tsurutani et al.,2014].The estimate is made from satellite data obtained ahead of the near-Earth shock or near the Lagrange point L1 of the Sun - Earth system. The magnetic storm intensity is determined from extreme $D s t, S Y M-H$, and $K_{\mathrm{p}}$ indices.
Ionospheric storms are generally studied using the parameters $f_{\mathrm{o}} \mathrm{F} 2$ or $N_{\mathrm{m}} \mathrm{F} 2=1.24 \mathrm{E} 4 \cdot f_{\mathrm{o}} \mathrm{F} 2^{2}$. Here $f_{\mathrm{o}} \mathrm{F} 2$ is the F2-layer critical frequency measured by vertical sounding stations. The difference between current and background values of $f_{\mathrm{o}} \mathrm{F} 2 / N_{\mathrm{m}} \mathrm{F} 2$ is used to determine the type of ionospheric disturbance developing in the ionospheric region of interest [Bryunelli,Namgaladze, 1988; Buonsanto, 1999; Goodman, 2005]. Rodger et al. [1989] proposed to use the disturbance index $\ln \left(N / N_{0}\right)$, where $N$ and $N_{0}$ are respectively the current and background (measured on magnetically quiet days) values of $N_{\mathrm{m}} \mathrm{F} 2$, to estimate ionospheric conditions. Wang et al. [2014] and Chen et al. [2014] put forward a method for determining the local and planetary indices of ionospheric disturbances from aperiodic component of $f_{\mathrm{o}} \mathrm{F} 2$ sets. However, these indices have not gained widespread acceptance yet.

It is important to note that the insufficient spatial resolution of data obtained from ground and satellite ionosondes preclude the reproduction of the global pattern of ionospheric storm development. To overcome this shortcoming, most current studies use total electron content (TEC) data [Mendillo, 2006; Borries et al., 2016; Dmitriev et al., 2017]. TEC variations can, however, differ greatly from $N_{\mathrm{m}} \mathrm{F} 2$ variations during magnetic storms (see, e.g., [Liu et al., 2016] and literature therein). This casts doubt on the validity of the use of 
TEC data for devising and testing models that adequately reflect the disturbed ionosphere dynamics and, accordingly, radio wave propagation conditions. Furthermore, the integrated nature of TEC values does not allow us to keep track of the electron density in the E-region, which, along with the F-region, strongly affects the radio wave propagation conditions. The study of the ionosphere with ionosondes is therefore still relevant.

The purpose of our work is to compare the ionospheric responses to the severe geomagnetic storms of December 14-16, 2006 and December 19-22, 2015. These storms are similar in intensity, season, and onset time. The relevance of the comparative analysis of events occurring in the same season and results of their simulation has been substantiated in [Kalita et al., 2016; Zhang et al., 2017; Dmitriev et al.,2017], where the strong magnetic storms of March 17-19, 2013 and 2015 with $D s t_{\min }=-132$ and -222 nT respectively were examined. Dmitriev et al. [2017] have further considered the March 8-9, 2008 moderate storm $\left(D s t_{\min }=-86 \mathrm{nT}\right)$. They obtained a quantitative agreement between values calculated from the global self-consistent model of the thermosphere, ionosphere, and protonosphere (TIP GSM) and experimental values of $N_{\mathrm{m}} \mathrm{F} 2$ for the storm in 2008, a qualitative agreement for the storm in 2013, and a complete disagreement for the storm in 2015, the strongest of those under study. Considerable differences between ionospheric parameters measured and obtained with the best known models for strong magnetic storms have been observed in [Buonsanto, 1999]. This points to the need to identify all relationships between heliospheric-magnetospheric-ionosphericthermospheric processes, which should be taken into account in modeling the ionospheric response to a strong magnetic storm.

Our study is based on data acquired with groundbased ionosondes in the same region of East Asia. This enables us to partially eliminate the internal factors mentioned above, and thereby clarify the relationship between ionospheric storms, magnetic storms, and their interplanetary drivers. For a more detailed study, we will supplement vertical sounding data with data from radio paths passing through the region of interest and with GPS TEC data. Moreover, the use of the ionosonde network covering latitudes from $18^{\circ}$ to $69^{\circ} \mathrm{N}$ allows us to gain new information on relationships between the processes that cause ionospheric disturbances in different latitudinal zones.

Our paper is structured as follows. In Section 1, we compare the main characteristics of magnetic storms and their interplanetary drivers; in Section 2, ionospheric responses to magnetic storms. In Section 3, we explore the possible causes for the differences in the dynamics of ionospheric disturbances during two storms; in Section 4, we summarize the results of the study.

\section{MAGNETIC STORMS AND THEIR INTERPLANETARY DRIVERS}

The storms of December 14-16, 2006 and December 19-22, 2015 we deal with are similar in season, onset time, and intensity. They began at around 14 and 16 UT eight days and three days before the winter solstice, and had $D s t_{\min }=-162$ and $-155 \mathrm{nT}$ respectively.For brevity, we introduce the notations S2006 and S2015 for the former and latter storms respectively.

Variations in the geomagnetic indices during the storms are shown in Figure 1; geoeffective parameters of the solar wind and IMF, in Figure 2. Plots in Figure 2 are constructed from ACE data for S2006 and from WIND data for S2015. During the measurements, the satellites were near the Lagrange point L1 of the Sun - Earth system at a distance of $\sim 42 R_{\mathrm{E}}$ and $\sim 27 R_{\mathrm{E}}$ ( $R_{\mathrm{E}}$ is the Earth radius) from the $\mathrm{X}_{\mathrm{GSE}}$ axis and provided adequate information about characteristics of the interplanetary medium affecting the magnetosphere [King, 1986; Ericsson et al., 2000]. Basing on SYM- $H$ trends, we determine the intervals corresponding to different storm phases (see Table 1). Boundaries of the intervals are shown in Figure 1 by vertical lines. Vertical lines in Figure 2 correspond to the lines presented in Figure 1 and thus bound the interplanetary structures whose time of arrival to the subsolar point of the magnetosphere coincides with respective storm phases. The moments of UT marked off in Figure 2 are identified by transferring fragments of heliospheric plasma from the satellite to the subsolar point of the magnetosphere with a velocity $V_{\mathrm{sw}}$. The lines denoted by SSC (storm sudden commencement), M , R1, and R2 indicate storm sudden commencements, beginning of their main, early, and late recovery phases respectively in the first and subsequent Figures. The M2 line marks the beginning of the second decrease in $S Y M-H$, i.e. the beginning of the second step of the S2015 main phase.

Under the Dst and SYM-H plots are variations of a three-hour $K_{\mathrm{p}}$ index, minute $A E$ and PCN/PCS indices. The $K_{\mathrm{p}}$ index is a measure of planetary magnetic activity; $A E$, magnetic disturbances in the auroral zone. Polar cap indices ( $P C N$ and PCS), determined using magnetic data from Thule and Vostok polar stations, correspond to the strength of the geoeffective interplanetary electric field (IEF) acting on the magnetosphere [Troshichev et al., 2006].

Using plots of Figures 1 and 2, let us list in chronological order the features that most clearly represent the similarity and difference between the magnetic storms and their interplanetary drivers.

1. The plots of Dst variations presented on the website [http://wdc.kugi.kyoto-u.ac.jp/wdc/Sec3.html] show that the average level of geomagnetic activity for five days prior to the storms was higher in December 2006 (Dst -30 nT, $K_{\mathrm{p}} \sim-3$ ) than that in December 2015 (Dst $10 \mathrm{nT}, K_{\mathrm{p}} \sim 2$ ). An hour before the former storm, Dst $\sim 25$ nT, $K_{\mathrm{p}} \sim 2$; an hour before the latter, Dst $\sim \mathrm{nT}$ and $K_{\mathrm{p}} \sim 1$. Thus, Earth's magnetosphere was less stable at SSC of S2006 than that at SSC of S2015.

2. The solar wind radial velocity and density increased up to $V_{\mathrm{sw}} \sim 900 \mathrm{~km} / \mathrm{s}$ and $N_{\mathrm{sw}} \sim 9 \mathrm{~cm}^{-3}$ at the leading edge of the S2006 driver; up to $V_{\mathrm{sw}} \sim 480 \mathrm{~km} / \mathrm{s}$ and $N_{\text {sw }} \sim 20 \mathrm{~cm}^{-3} 3$ at the leading edge of the S2015 driver. The relatively low velocity and high density of the solar wind were observed throughout the region of the S2015 interplanetary driver. 

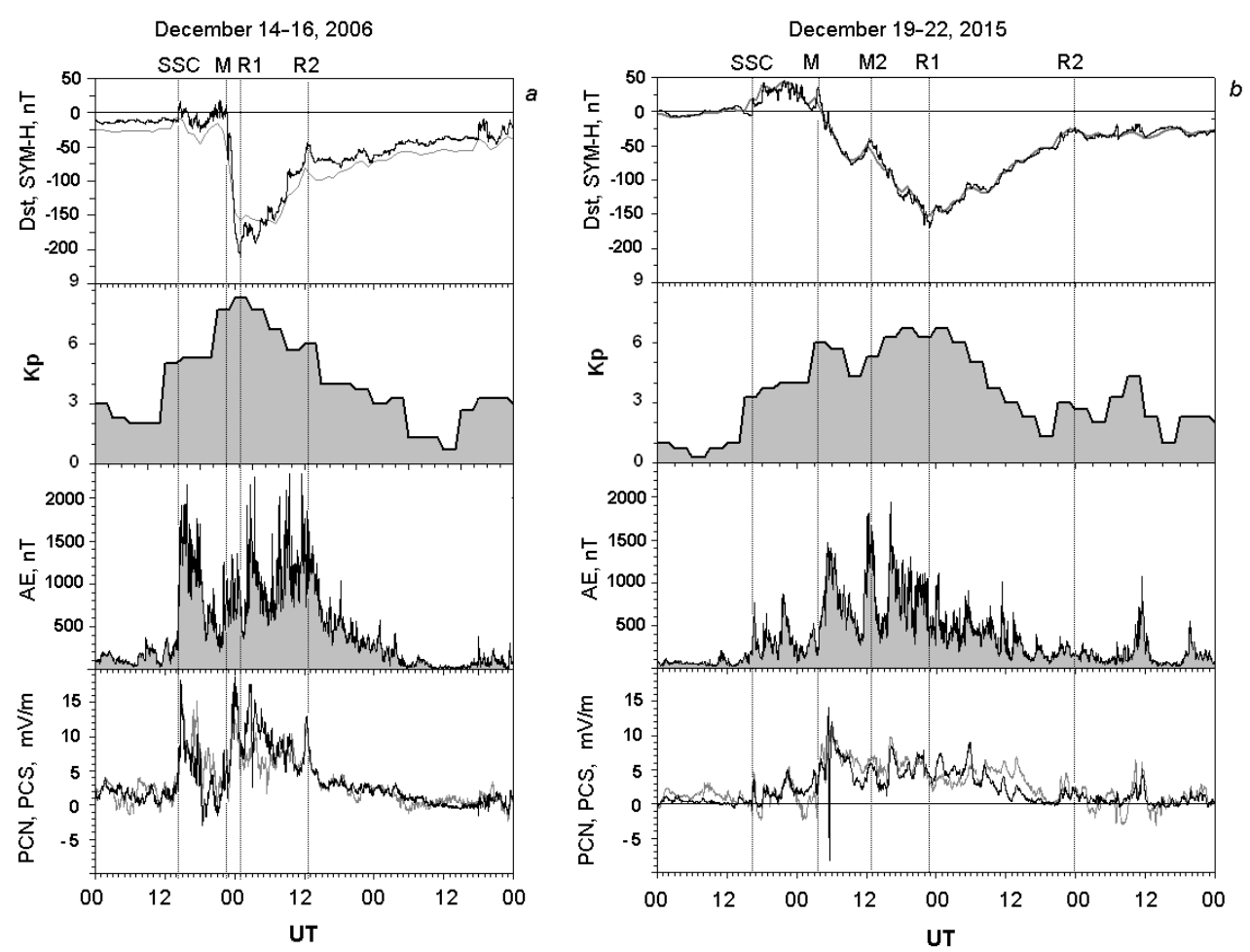

Figure 1. From top to bottom: variations in SYM-H (black line) and Dst (gray line) indices, $K_{\mathrm{p}}, A E$ indices, and PCN/PCS (black/gray line) indices for S2006 ( $a$ ) and S2015 (b) storms
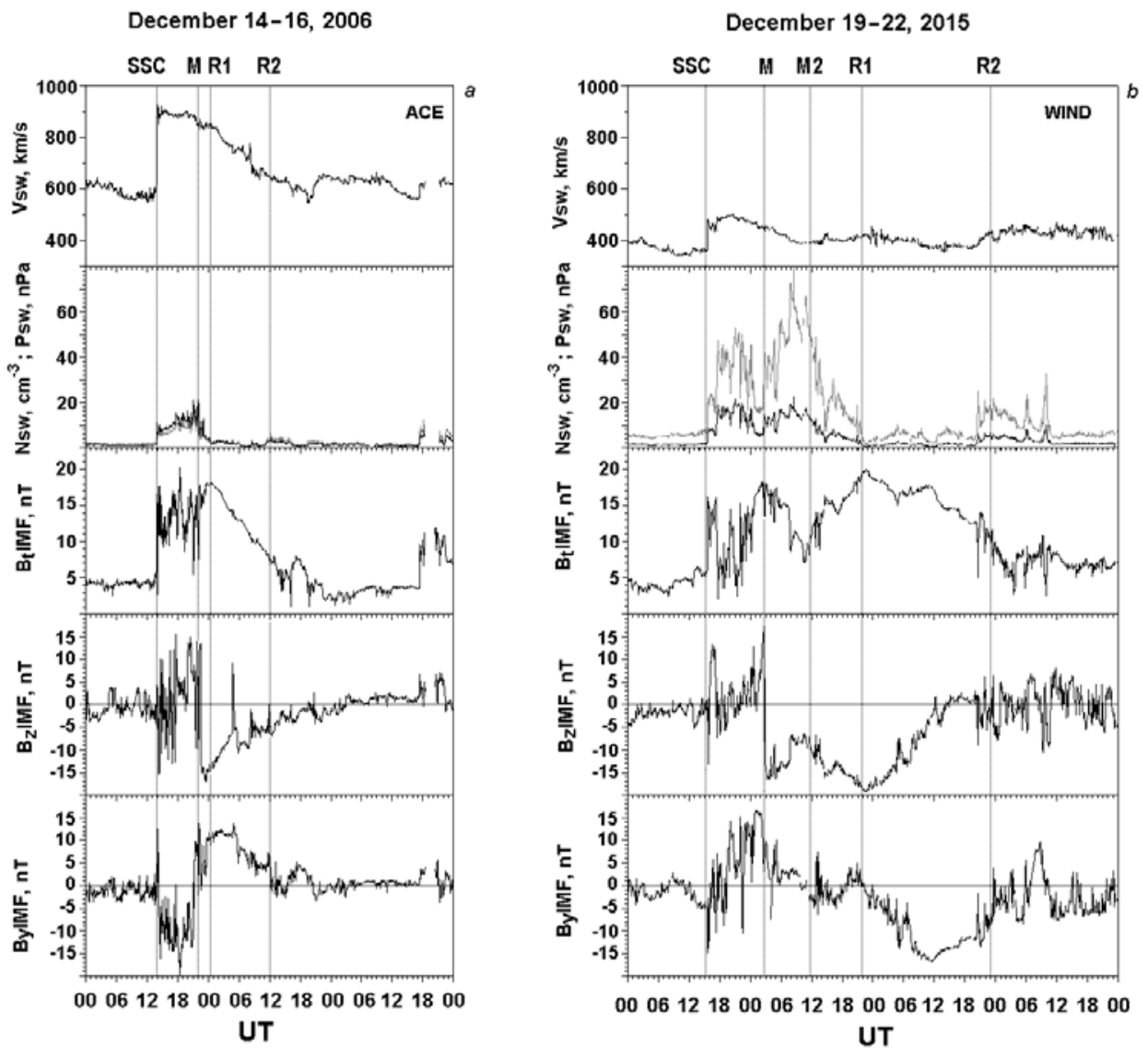

Figure 2. Variations of the solar wind velocity $\left(V_{\mathrm{sw}}\right)$, ram pressure, and density $\left(P_{\mathrm{sw}}\right.$ and $N_{\mathrm{sw}}$; black and gray lines respectively), of the IMF modulus ( $B_{\mathrm{t}}$ ), vertical $\left(B_{\mathrm{z}}\right)$, and azimuthal $\left(B_{\mathrm{y}}\right)$ components in the GSM coordinate system (from top to bottom). The vertical lines represent the beginning and end of magnetic storm phases marked in Figure 1 and listed in Table 1 
Geomagnetic storm phases

\begin{tabular}{|c|c|c|c|c|c|c|c|c|c|c|}
\hline \multirow{4}{*}{ Storm } & \multicolumn{10}{|c|}{ Storm phase } \\
\hline & \multicolumn{2}{|c|}{ initial } & \multicolumn{4}{|c|}{ main } & \multicolumn{4}{|c|}{ recovery } \\
\hline & \multirow[b]{2}{*}{$\begin{array}{l}\text { UT, } \\
\text { day }\end{array}$} & \multirow[b]{2}{*}{$\begin{array}{l}\Delta T, \\
\mathrm{hr}\end{array}$} & \multirow[b]{2}{*}{$\begin{array}{l}\text { UT, } \\
\text { day }\end{array}$} & \multirow[b]{2}{*}{$\begin{array}{c}\Delta T, \\
\mathrm{hr}\end{array}$} & \multicolumn{2}{|l|}{ step } & \multicolumn{2}{|l|}{ early } & \multicolumn{2}{|c|}{ late } \\
\hline & & & & & $\begin{array}{l}\text { UT, } \\
\text { day }\end{array}$ & $\begin{array}{l}\Delta T, \\
\mathrm{hr}\end{array}$ & $\begin{array}{l}\text { UT, } \\
\text { day }\end{array}$ & $\Delta T, \mathrm{hr}$ & $\begin{array}{l}\text { UT, } \\
\text { day }\end{array}$ & $\Delta T, \mathrm{hr}$ \\
\hline $\begin{array}{c}\text { December } \\
\text { 14-16, } \\
2006\end{array}$ & $\begin{array}{c}14: 15- \\
\text { 22:29, } \\
\text { December } \\
14\end{array}$ & 8.25 & $\begin{array}{c}\text { 22:29-00:55, } \\
\text { December } \\
\text { 14-15 }\end{array}$ & 2.5 & & & $\begin{array}{l}\text { 00:55-12:30, } \\
\text { December } 15\end{array}$ & 11.5 & $\begin{array}{c}\text { 12:30-17:56, } \\
\text { December } \\
\text { 15-16 }\end{array}$ & 29.5 \\
\hline $\begin{array}{c}\text { December } \\
\text { 19-24, } \\
2015\end{array}$ & $\begin{array}{c}16: 18- \\
\text { 03:42, } \\
\text { December } \\
\text { 19-20 }\end{array}$ & 11.5 & $\begin{array}{l}\text { 03:42-22:52, } \\
\text { December } 20\end{array}$ & 19 & $\begin{array}{l}\text { 03:42-09:34, } \\
\text { 12: 48-22: 52, } \\
\text { December 20, }\end{array}$ & $\begin{array}{c}6 \\
10\end{array}$ & $\begin{array}{c}\text { 22:52-23:52, } \\
\text { December } \\
\text { 20-21 }\end{array}$ & 25.0 & $\begin{array}{c}\text { 23:52-13:22 } \\
\text { December } \\
\text { 21-24 }\end{array}$ & 61.4 \\
\hline
\end{tabular}

3. Ram pressure jumps differing in amplitude ( $\Delta P_{\mathrm{sw}} \sim 9$ and $\sim 4 \mathrm{nPa}$ at the leading edges of the $\mathrm{S} 2006$ and S2015 drivers) caused almost similar jumps of $\triangle S Y M-H \sim 22$ and $24 \mathrm{nT}$, but different changes of the $A E$ index. In the first case, the peak-like increases in $A E$ up to $1000-2100 \mathrm{nT}$ began immediately after SSC and lasted for $\sim 4$ hrs. In the second, the SSC was followed by a peak of $A E \sim 760 \mathrm{nT}$, which lasted for $\sim 0.5 \mathrm{hr}$. The $A E$ peaks suggest the development of substorm-like events whose triggers might have been changes of interplanetary medium parameters including those at the leading edges of the interplanetary drivers of the storms. These edges are called interplanetary shocks [Bargatze et al., 1985; Zhou, Tsurutani,2001; Yue et al.,2010]. The difference between the responses of auroral currents to the shocks could be caused by at least three factors. These are differences between $\Delta P_{\mathrm{sw}}$ values, initial conditions of the magnetosphere-ionosphere system and IEF strengths (see the PCN and PCS plots in Figure 1).

4. The plots drawn in Figure 1 and the data listed in Table 1 show that the storms differ most widely in duration $(\Delta T)$ and structure of the main phase. The S2006 storm is one-step, and the S2015 storm is two-step. During the $2.5 \mathrm{hr}$ main phase of the former storm, the $S Y M-H$ index decreased with a mean rate of $\sim-90 \mathrm{nT} / \mathrm{hr}$ from $S Y M-H \sim 0 \mathrm{nT}$ to minimum $S Y M-H=-211 \mathrm{nT}$. During the $19 \mathrm{hr}$ main phase of the latter storm, $S Y M-H$ decreased from 34 to $-77 \mathrm{nT}$ (the first step), increased to $-40 \mathrm{nT}$, and decreased again to $S Y M-H_{\min }=-170 \mathrm{nT}$ (the second step) within 6, 9, and 19 hrs after the beginning of this phase. In this case, the mean rate of the SYM- $H$ decrease was $\sim 10 \mathrm{nT} / \mathrm{hr}$. Extreme $K_{\mathrm{p}}$ was $8+$ during the former storm and 7- during the latter.

5 . The $B_{\mathrm{z}}$ plots presented in Figure 2 show that the main phases of the two storms correspond in time to the regions of the southward IMF $B_{\mathrm{z}}$ component. At the leading edges of these regions there was a fast, $\sim 10 \mathrm{~min}$, north-to-south turn of $B_{\mathrm{z}}$, which caused an IEF enhancement, with $B_{\mathrm{z}}$ equally decreasing from $\sim 15$ to $-15 \mathrm{nT}$. A part of the S2006 driver responsible for the generation of the main phase comprised a magnetic cloud - a region of the magnetic field that was strong, slowly varied in strength and direction with low solar wind density: $N_{\mathrm{sw}} \sim 2 \mathrm{~cm}^{-3}$. It is believed that interplanetary drivers of this type are the most powerful heliospheric sources of geomagnetic storms [Tsurutani, Gonzalez, 1997; Gonzalez et al.,2002; Borovsky, Denton, 2010]. The high solar wind density in the region associated with the S2015 main phase of the two-phase enhancement of negative IMF $B_{z}$ does not allow us to consider this structure as the magnetic cloud.

6. Judging from maximum $P C N$ and PCS, the strength of IEF and, accordingly, of the magnetospheric convection field during the main phase of S2006 was $~ 1.5$ times higher than that during the first stepof S2015. This difference is associated with the velocity of the S2015 driver, which is lower than that of S2006, and with the weak IMF $B_{y}$ component in the region responsible for the generation of the main phase of the latter storm. Despite the strong magnetospheric convection, $A E$ during the S2006 main phase was 1.5-2 times lower than that during the S2015 main phase. Zolotukhina et al. [2012] have demonstrated that during the S2006 main phase the center of the westward jet was in the sub-auroral zone, not in the auroral one. Hence it follows that in this case $A L$ and $A E$ underestimate the auroral activity level.

7. The early recovery phases of S2006 and S2015 correspond to periods of non-monotonic decrease in the southward IMF $B_{\mathrm{z}}$ component. The S2006 early recovery phase developed when $B_{\mathrm{y}}>0$. At the end of this phase, auroral activity increased with an increase in $A E$ to $2000 \mathrm{nT}$. According to the results obtained by Troshichev et al. [1986], the increase might have been triggered by the change of the IMF $B_{\mathrm{y}}$ sign from positive to negative. The S2015 early recovery phase developed at $B_{\mathrm{y}}<0$. Velichko et al. [2002] has indicated that with this orientation of IMF the intensity of geomagnetic disturbances in the auroral zone of the Southern Hemisphere is higher than that in the auroral zone of the Northern Hemisphere.

8. The differences between characteristics of the interplanetary drivers of the storms are connected with the differences between their primary sources. An external driver of S2006 was the interplanetary coronal mass ejection (ICME) that appeared around 02:40 UT on December 13 after the X3.4/4B flare [http://www.solen.info/solar/old_reports]. The complex interplanetary driver of S2015 was formed by the interaction of two ICMEs whose occurrence was recorded at 09:36 and 14:24 UT on December 16 [https://cdaw.gsfc.nasa.gov/CME_list]. The former ejection accompanied the C6/1F flare and moved with deceleration; the latter was caused by a filament eruption and moved with acceleration. 


\section{IONOSPHERIC DISTURBANCES}

To analyze the ionospheric response to the magnetic storms, we have used data from ionospheric stations located in East Asiaand from three oblique sounding radio paths. Coordinates of the ionospheric stations, transceivers along the radio paths, and their midpoints are given in Table 2. Ionospheric activity was estimated relative to the background values obtained by averaging ionospheric parameters measured under quiet geomagnetic conditions (on December 5 and 13, 2006, and December 17 and 18, 2015). Variations in $f_{0} F 2$, cutoff frequency of the sporadic $\mathrm{E}$ layer $\left(f_{\mathrm{f}} \mathrm{E}_{\mathrm{s}}\right)$, as well as in maximum observed frequencies of one-hop (MOF1F) and two-hop (MOF2E $\mathrm{E}_{\mathrm{s}}$ ) modes are shown in Figures 3, 4 for S2006 and S2015 respectively.

\subsection{Initial phase}

During the two SSC, the ionosonde chain of interest was in the night sector. In both the cases, the sporadic $\mathrm{E}$ layers $\left(E_{s}\right)$ characteristic of the diffuse precipitation zone were observed at Zhigansk and Yakutsk highlatitude stations before and after the SSC. The difference between the responses of the high-latitude ionosphere to the initial phases of the storms is a sharp change of ionospheric parameters for S2006 and the absence of marked changes for S2015.Figure 3 shows that Zhigansk station observed diffuse reflections from the F2 layer with increased $f_{0} F 2$ only during the first hour; and reflections from intense $E_{s}$ layers, which alternated with periods of complete absorption, during the entire initial phase. At that time, Yakutsk station observed the $E_{\mathrm{s}}$ layers and diffuse reflections from the $\mathrm{F} 2$ layer whose critical frequencies were 1.5-2 times higher than those under quiet geomagnetic conditions.
At Magadan mid-latitude station during the nighttime of S2006 there were no reflections on ionograms. This may suggest that it was near the main ionospheric trough (MIT). This conclusion is confirmed by oblique sounding data. Along the Magadan - Irkutsk path there were no reflections of regular modes. Hence, the northern section of the path from the transmitter toits midpoint was located near MIT. From 17:40 to 19:30 UT on December 14, only abnormal diffuse signals that which propagated outside the great-circle arc were detected. This also suggests that the MIT polar wall was close to the HF radio wave propagation path. Along the meridional Norilsk - Irkutsk path, only the $2 \mathrm{E}_{\mathrm{s}}$ mode was recorded, thereby indicating that the $\mathrm{E}_{\mathrm{s}}$ layers developed along the propagation path. During the nighttime of S2015 there was the F2 layer with critical frequencies close to background values. Thus, we can conclude that in the S2015 initial phase the MIT boundaries were further north than those in the S2006 initial phase.

At other mid-latitude stations during the initial phase of both the storms, $f_{\mathrm{o}} \mathrm{F} 2$ significantly differed from the background one. The main difference in the mid-latitude ionosphere response is associated with the appearance of flat sporadic layers at Irkutsk and Mohe stationsduring S2015. Note that the initial phase of S2015 was longer-term than that of S2006 and covered the dawn sector. During morning hours, Magadan, Irkutsk, and Khabarovsk stations observed wave-like fluctuations of $f_{\mathrm{o}} \mathrm{F} 2$ due to the passage of medium-scale traveling ionospheric disturbances (TIDs) showing as cusps and hooks on a high-frequency part of ionograms.

Coordinates of ionospheric stations, transceivers, and midpoints of radio paths

\begin{tabular}{|c|c|c|c|}
\hline \multirow{2}{*}{$\mathrm{N}$} & \multirow{2}{*}{ Stations } & \multicolumn{2}{|c|}{ Geographic coordinates } \\
\hline & & Latitude, ${ }^{\circ} \mathrm{N}$ & Longitude, ${ }^{\circ} \mathrm{E}$ \\
\hline 1 & Norilsk & 69.4 & 88.1 \\
\hline 2 & Zhigansk & 66.3 & 123.4 \\
\hline 3 & Yakutsk & 62.0 & 129.9 \\
\hline 4 & Magadan & 60.0 & 151.0 \\
\hline 5 & Irkutsk & 52.5 & 104.0 \\
\hline 6 & Mohe & 52.0 & 122.5 \\
\hline 7 & Khabarovsk & 48.5 & 135.1 \\
\hline 8 & Wakkanai & 45.4 & 141.7 \\
\hline 9 & Beijing & 40.0 & 116.3 \\
\hline 10 & Jeju & 33.1 & 126.3 \\
\hline 11 & Yamagawa & 31.2 & 130.6 \\
\hline 12 & Okinawa & 26.3 & 127.8 \\
\hline 13 & Sanya & 18.3 & 109.4 \\
\hline 14 & $\begin{array}{l}\text { Magadan-Irkutsk } \\
\text { (midpoint) }\end{array}$ & 58.5 & 122.8 \\
\hline 15 & $\begin{array}{l}\text { Khabarovsk-Irkutsk } \\
\text { (midpoint) }\end{array}$ & 51.25 & 119.6 \\
\hline 16 & $\begin{array}{l}\text { Norilsk-Irkutsk } \\
\text { (midpoint) }\end{array}$ & 60.9 & 98.0 \\
\hline
\end{tabular}




\section{December 14-16, 2006}
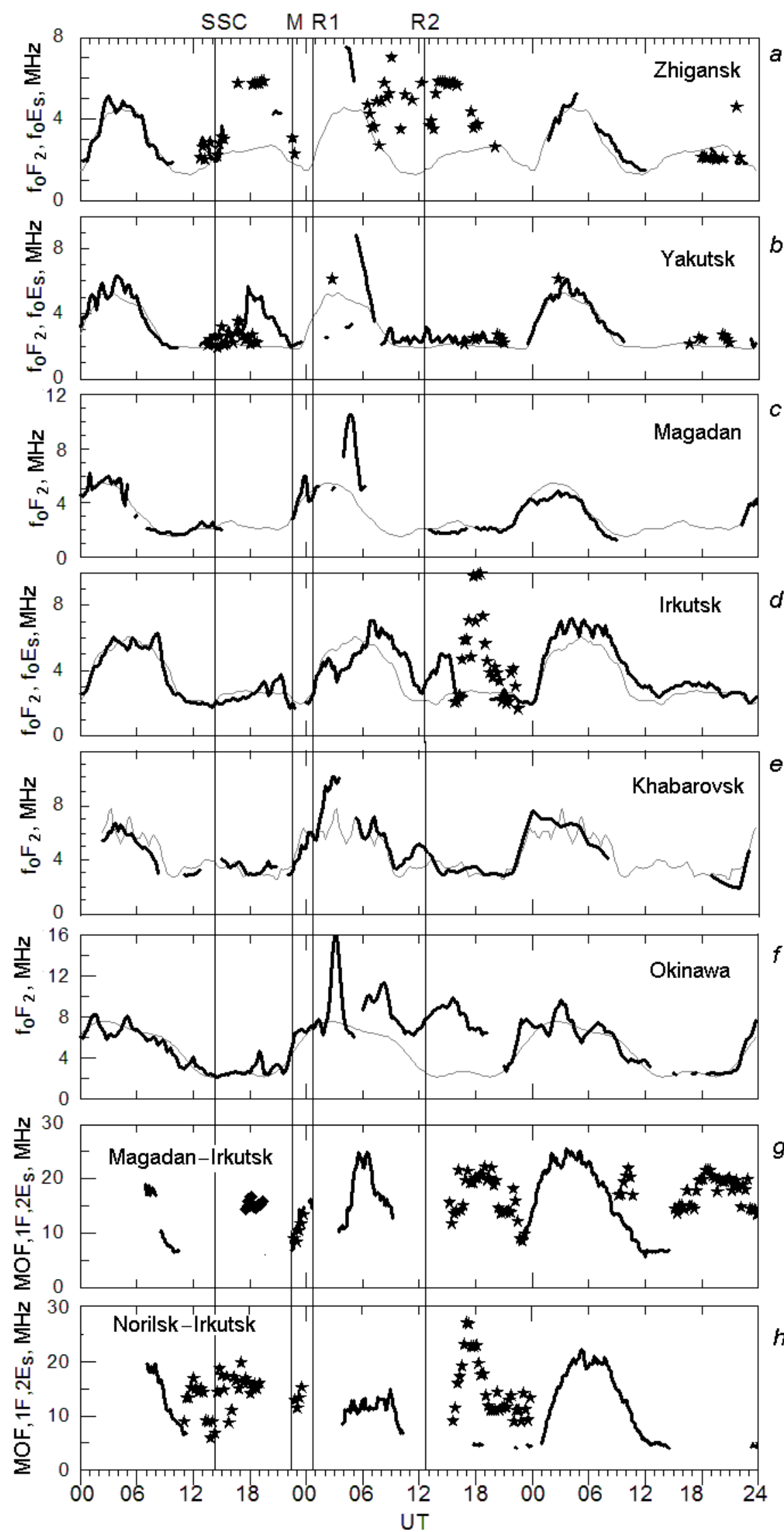

Figure 3. Variations in the F2-layer critical frequency ( $a-f)$ under quiet (gray line) and disturbed (black line) conditions, in the $\mathrm{E}_{\mathrm{s}}$-layer cutoff frequency ( $a, b, d$, asterisks) at the ionosonde network, and in maximum observed frequencies $(g, h)$ of onehop (MOF1F, black line) and two-hop (MOF2E $\mathrm{E}_{\mathrm{s}}$, asterisks) modes along the Magadan - Irkutsk and Norilsk - Irkutsk paths during the December 14-16, 2006 magnetic storm. Squares mark MOF signals propagating outside the great circle arc 
December 19-22, 2015
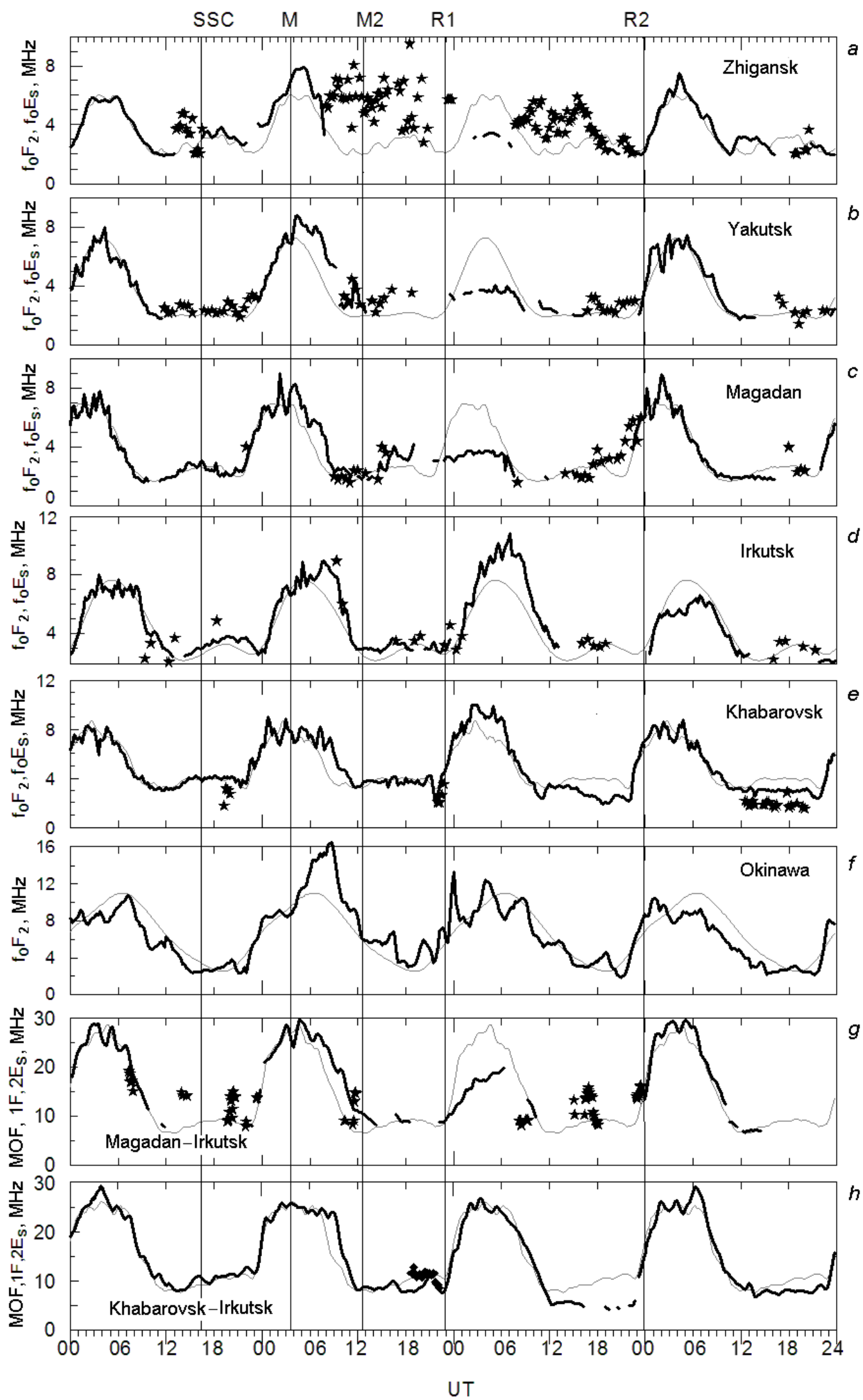

Figure 4. Variations in the F2-layer critical frequency $(a-f)$ under quiet and disturbed conditions, in the $\mathrm{E}_{\mathrm{s}}$-layer cutoff frequency $(a-e)$ at the ionosonde network, and in $\operatorname{MOF}(g, h)$ of one-hop $(1 \mathrm{~F})$ and two-hop $\left(2 \mathrm{E}_{\mathrm{s}}\right)$ modes over the Magadan - Irkutsk and Khabarovsk - Irkutsk paths during the December 19-22, 2015 magnetic storm. Notations are the same as in Figure 3 


\subsection{Main phase}

The S2006 main phase began in the dawn sector; and the S2015 one, in the pre-noon sector. The most notable increases in $f_{\mathrm{o}} \mathrm{F} 2$ during S2006 occurred in the dawn sector at the stations located in $130-150^{\circ} \mathrm{E}$ longitudes. At that time inthe high-latitude stations there were no echo signals on ionograms due to absorption.

The first step of the S2015 main phase featured the development of a positive disturbance at all latitudes. A marked increase in $f_{0} \mathrm{~F} 2$ was observed at Zhigansk ( 30-35 \%), Yakutsk ( 40-50\%), Irkutsk ( 30-40\%), and Okinawa ( $\sim 60-70 \%)$ stations. This positive disturbance covered daylight and evening hours. Judging from the morphological characteristics, it might have been due to the enhancement of the equatorward thermospheric wind component. The disturbance developed simultaneously with peak-like increases in PCN, PCS, and $A E$, which indicated the enhancement of the magnetic convection field and auroralelectrojets, as well as with multiple increases in $N_{\mathrm{sw}}$ to $40-70 \mathrm{~cm}^{-3}$ able to cause an increase in fluxes of particles precipitating into the high-latitude ionosphere.

The plot of $\mathrm{H}$-component variations drawn in Figure $6, d$ shows that Tiksiauroral station observed only weak enhancements of the eastward electrojet. Such enhancements often occur even in magnetically quiet conditions. They cannot heat the atmosphere sufficiently to generate the positive element of the ionospheric storm, which was observed in the longitudinal sector of interest. We believe that in this case the positive disturbance was caused by heating of the atmosphere in the nightside of the auroral zone and in the vicinity of the cusp.

On December 20, 2015 between 07:30-10:00 UT (15:30-18:00 LT), the high-latitude stations observed a sharp evening drop in the critical frequency typical for disturbed conditions, which was followed by the appearance of intense blanketing sporadic layers. At night (during the second step of the main phase), Magadan, Irkutsk, and Khabarovsk mid-latitude stations observed flat $\mathrm{E}_{\mathrm{s}}$ layers. On the same day at the end of the second step (at 21: 30 2145 UT), the critical frequency, according to Khabarovsk station data, decreased to $2 \mathrm{MHz}$, and on oblique sounding ionograms from the Khabarovsk - Irkutsk path were abnormal signals propagating outside the great circle arc. Okinawa low-latitude station observed wave-like fluctuations of $f_{0} \mathrm{~F} 2$, which also continued during the recovery phase of the storm.

Referring to the MOF plots, during the S2006 main phase propagation of HF radio signals along the Magadan - Irkutsk path was performed by the $1 \mathrm{~F}$ and $2 \mathrm{E}_{\mathrm{s}}$ modes; and along the Norilsk - Irkutsk path, only by the $2 \mathrm{E}_{\mathrm{s}}$ mode. During the S2015 main phase, this mode was observed only along the Magadan - Irkutsk path before the onset of the second step of the main phase.

\subsection{Recovery phase}

During the early recovery phases of both the storms, strong variations of ionospheric parameters occurred in all latitudes.

During S2006, Zhigansk station observed no reflections in pre-noon hours due to increased absorption [Zolo- tukhina et al., 2012]. During daylight hours, Yakutsk station occasionally recorded extremely low $f_{0} \mathrm{~F} 2$. The main feature of the behavior of $f_{0} F 2$ is the generation of a short-term positive disturbance observed at Zhigansk station within 04:15-05:00 UT, at Yakutsk within 05:1506:15 UT, at Magadan within 04:00-05:30 UT, at Khabarovsk within 02:30-03:30 UT, at Okinawa within 02:4504:00 UT on December 15, 2006. A similar short-term MOF increase occurred over the Magadan - Irkutsk path within 05:00-06:30 UT. Over the Norilsk - Irkutsk path there was no such an increase in MOF. In the remaining hours, the mid-latitude stations recorded critical frequencies that were significantly higher than the background ones. An exception are the $f_{\mathrm{o}} \mathrm{F} 2$ variations at Khabarovsk station, where the F2-layer critical frequencies were close to the background values at that time.

During the S2015 recovery phase in the afternoon, Zhigansk, Yakutsk, and Magadan stations observed a negative disturbance such that $f_{0} \mathrm{~F} 2$ decreased 1.5-2 times relative to the background one. At that time over Irkutsk and Khabarovsk stations, positive disturbances developed.

Of particular interest is the appearance of intense blanketing $E_{\mathrm{s}}$ layers over Irkutsk station during the nighttime on December 15, 2006 (16:30-20:00 UT), which facilitate propagation of $\mathrm{HF}$ radio signals only by the $2 \mathrm{E}_{\mathrm{s}}$ mode along the Magadan - Irkutsk and Norilsk - Irkutsk paths. Note that on December 21, 2015 in the given UT period, Yakutsk, Magadan, and Irkutsk stations observed the $\mathrm{E}_{\mathrm{s}}$ layers, and recorded only the 2E s mode along the Magadan -Irkutsk path. Mohe station detected no reflections. Critical frequencies at Khabarovsk station and MOF along the Khabarovsk - Irkutsk path were significantly lower than the background ones. This might have been due to the slow recovery of the plasmasphere and, accordingly, of its conjugated ionosphere after the main phase of the magnetic storm [Romanova, Tashchilin, 2013; Tashchilin, Romanova,2014]. At Okinawa low-latitude station, the recovery phases of the storms were accompanied by wavelike fluctuations of $f_{\mathrm{o}} \mathrm{F} 2$.

Note that the wave-like fluctuations of $f_{\mathrm{o}} \mathrm{F} 2$ occurred both before the storms and during all of their phases. This is shown more clearly in Figure 5. Plots presented in Figure 5 are constructed from $1-5 \mathrm{hr} f_{\mathrm{o}} \mathrm{F} 2$ variations, separated from the initial series by a bandpass filter, which does not distort phase [Marmet, 1979]. Boundaries of the filter are determined from $f_{0} F 2$ spectra. In Figure 3 (for S2006), the wave-like fluctuations on the $f_{0} \mathrm{~F} 2$ plots are seen only at the stations located to the south of $48^{\circ} \mathrm{N}$. The filtered $f_{0} \mathrm{~F} 2$ series are presented for these stations in Figure 5, a. Figure 4 indicates that during S2015 disturbances of this type were also observed at Magadan and Yakutsk stations. However, because of long gaps in the initial sets, the plots of filtered $f_{0} \mathrm{~F} 2$ for these stations are not shown in Figure 5, $b$.

Notice that all of the five enhancements of the wave-like fluctuations to the level exceeding the prestorm one (two during S2006 and three during S2015) clearly seen in Figure 5, $a, b$ occurred on December 14-15, 2016 and December 19-21, 2015 at 21:0023:00 UT. For the longitudinal sector of interest, this corresponds to the vicinity of the dawn meridian. The first 

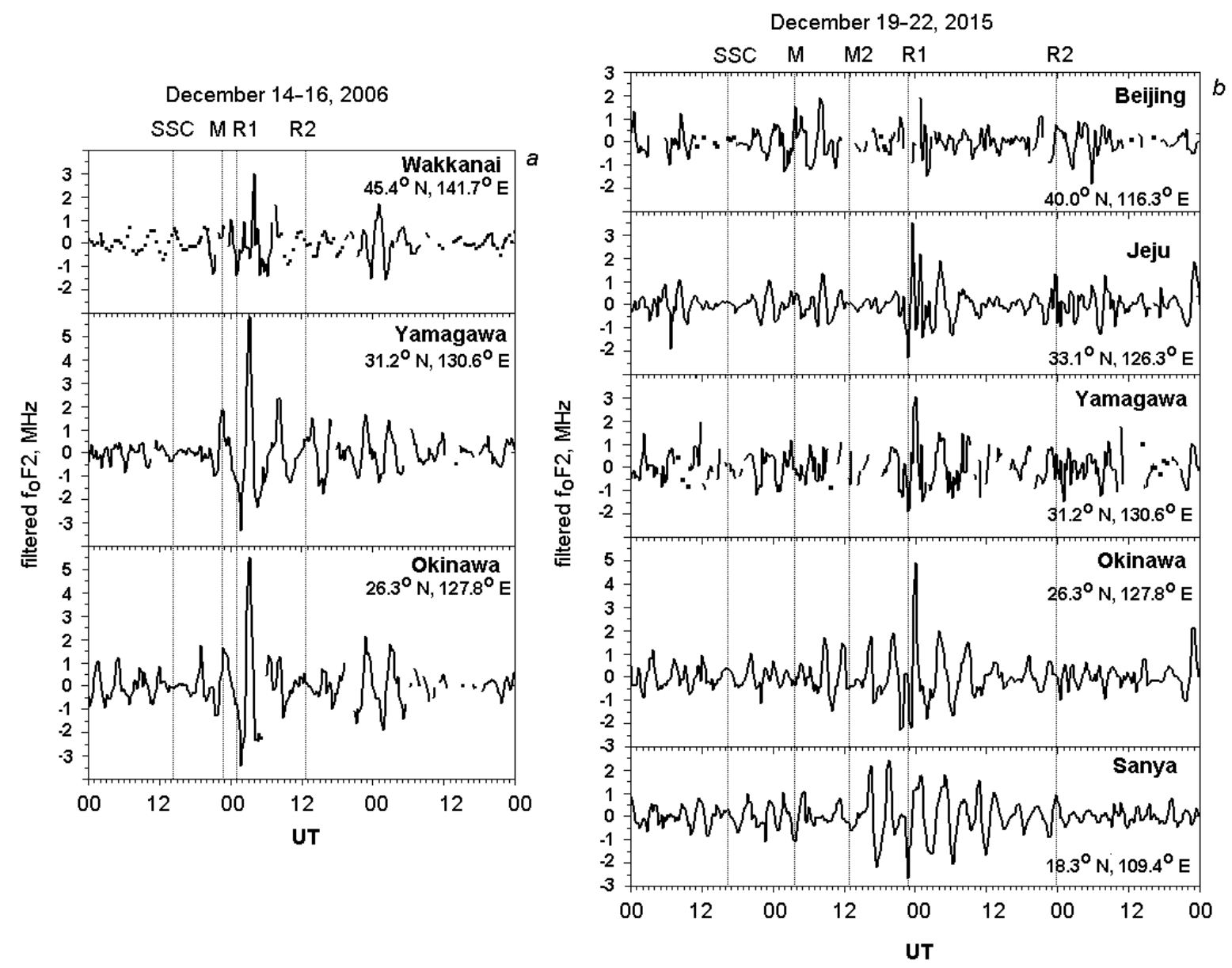

Figure 5. Variations in $f_{0} \mathrm{~F} 2$ with periods $T \leq 5 \mathrm{hr}$ observed during S2006 (a) and S2015 (b) in East Asia

of these two enhancements observed during S2006 has been analyzed by Lei et al. [2008]. Lei et al. [2008] showed that the wave-like fluctuations were induced by the superposition of TIDs arising from the Joule heating of the high-latitude atmosphere of the Northern and Southern hemispheres and propagating to the south and north respectively.

\subsection{Comparison}

Summarizing the facts described in Subsections 2.12.4, we point out the most obvious similarities and differences between the ionospheric storms considered.

2.4.1. In both the cases, the sporadic layers resulting from particle precipitation were observed at the subauroral stations both before the storms and during their initial phases. Differences between the nighttime ionospheric responses to the initial phases are manifested by the fact that the positive nighttime ionospheric disturbance $\left(f_{\mathrm{o}} \mathrm{F} 2\right.$ increase) and the sharp increase in $f_{\mathrm{o}} \mathrm{E}_{\mathrm{s}}$ were detected in the subauroral zone only during S2006, whereas the flat night side $\mathrm{E}_{\mathrm{s}}$ layers were observed in the mid-latitude zone (Irkutsk and Mohe stations) only during S2015.

2.4.2. During the December 19-22, 2015 storm, the pronounced ionospheric disturbances began with a positive daytime disturbance observed at all the ionospheric stations in the first step of the main phase. In the subau- roral zone, this disturbance was followed by a sharp drop in $f_{0}$ F2with subsequent appearance of intense blanketingE $E_{s}$ layers having cutoff frequencies close to those observed in the initial phase of S2006.

2.4.3. A specific feature of S2006 is the dramatic short-term increase in $f_{\mathrm{o}} \mathrm{F} 2$ observed on December 14 in the afternoon sector at Zhigansk, Yakutsk, and Magadan stations. Zolotukhina et al. [2012] have found that an abrupt increase in $f_{0} \mathrm{~F} 2$ over these stations corresponds in time to the passage of observation points under the sharp inner edge of the plasma sheet.

2.4.4. Pirog et al. [2006] have indicated that winter ionospheric storms developing over East Asia during the daytime recovery phase feature high-latitude negative and mid-latitude positive disturbances. This latitudinal distribution of disturbances did occur during daylight hours of the early recovery phases of both the storms. However, the transition from negative to positive disturbance took place during S2006 between Yakutsk and Magadan stations; and during S2015, to the south — between Magadan and Mohe stations.

\section{DISCUSSION}

Long-term studies of the ionosphere with ionosondes, which began in the mid-1920s, have formed an experimental basis for the classification of the main 
elements of ionospheric storms. This basis relies on presumed origin of the storms. Such a classification has been made, for example, by Prölss et al. [1991]. The authors have identified five basic elements of ionospheric storms in subauroral latitudes. Three of them arise from long-term or flash Joule heating of the atmosphere and extend equatorward; two others, from lowering of the latitude of auroral precipitation zone and main ionospheric trough. Further investigations have shown that a significant contribution to the dynamics of ionospheric storms is also made by prompt penetrating electric fields of magnetospheric origin and the "disturbed dynamo" field of thermospheric origin [Huang, 2013]. Effects of electric fields are most pronounced in the vicinity of the equatorial ionospheric anomaly.

Let us consider from this point of view the results of the comparative analysis of ionospheric storms reported in Section 2. The effects caused by the shift of largescale ionospheric structures to lower latitudes were observed on December 14, 2006 and December 20, 2015. According to [Prölss et al., 1991], the former (positive night disturbance, see Subsection 2.1) is connected with the extension of auroral ionization zone; the latter (sharp evening decrease in $f_{0} F 2$, see Subsection 2.2), with the MIT shift. changes in latitudes of the auroral oval, equatorial boundary of electron precipitation (inner edge of the plasma sheet), MIT bottom, and high-latitude TEC minimum along the meridian of $120^{\circ} \mathrm{E}$. The latitude of the inner edge of the plasma sheet was determined by a model [Kamide, Winningham, 1977]; the latitude of the MIT bottom, by an empirical model developed specifically for East Asia [Zherebtsov et al., 1986], in which the MIT latitude depends on the local time and $K_{\mathrm{p}}$ index. Coordinates of the auroral oval boundaries have been taken from the website [http://sd-

www.jhuapl.edu/Aurora/ovation/ovation_display.html].

The latitude of TEC minimum was estimated from the meridian profiles constructed from its values given on the website [http://cdaweb.gsfc.nasa.gov/cdaweb/istp_public] with latitudinal resolution of $2.5^{\circ}$.

Note the similarity between trends of the latitude of the structures shown in Figure 6, as well as the significant difference between latitudes of the MIT bottom and TEC minimum in the S2006 maximum. This difference can be explained by the significant equatorial shift of electrojets relative to the standard $A E$ stations shown in [Zolotukhina et al., 2012].

Figure $6, a, b$ for the Northern Hemisphere shows
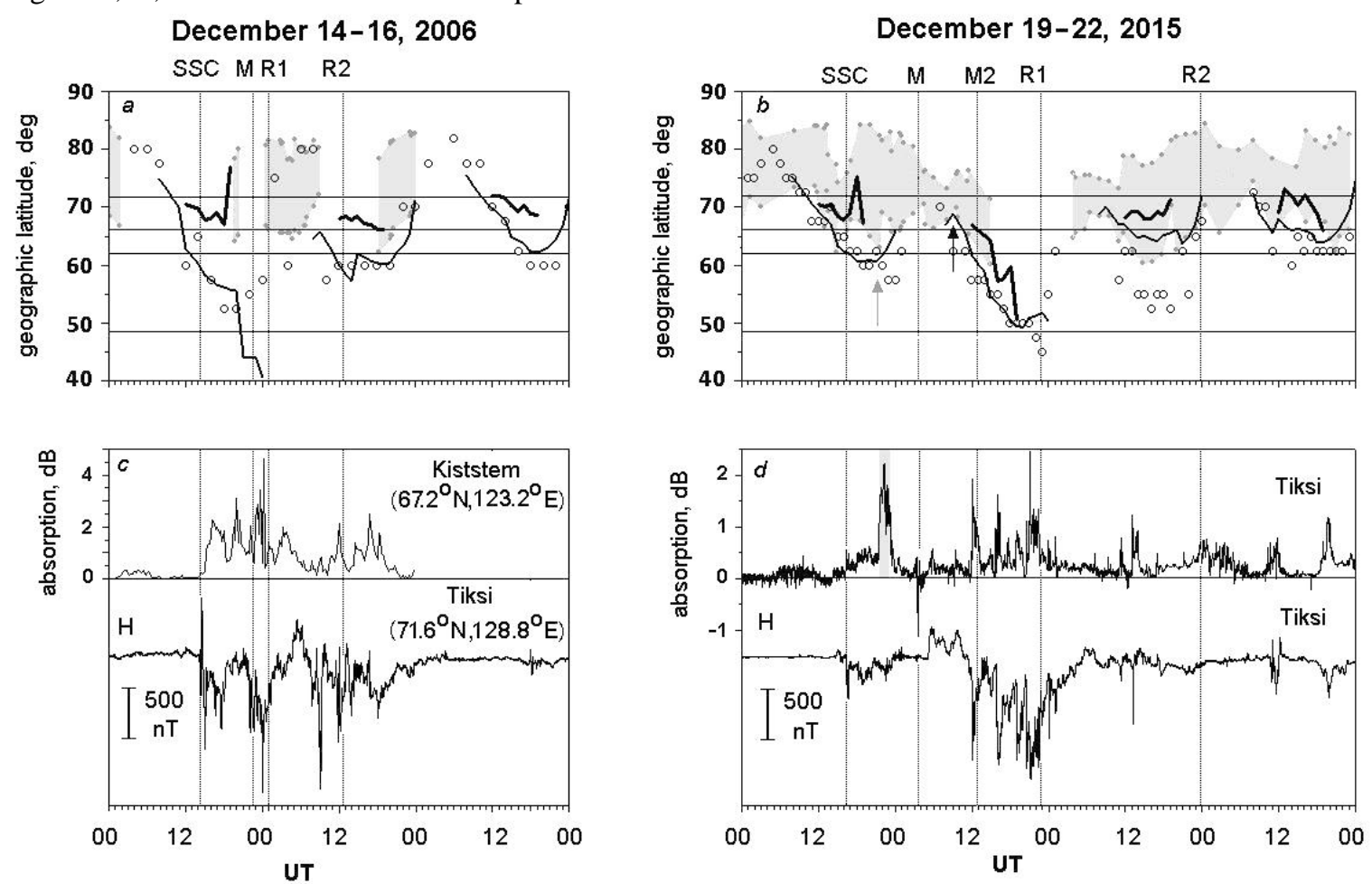

Figure 6. Variations in the geographic latitude of the equatorial boundary of diffuse precipitation zone (thick line), MIT (thin line), TEC minimum (circles), and auroral oval (gray figure and dots) along the meridian of $120^{\circ} \mathrm{E}$ for S2006 (a) and S2015 (b). Horizontal lines mark (from top to bottom) the latitudes of Tiksi, Zhigansk, Yakutsk, and Khabarovsk stations. Variations in the ionospheric absorption and magnetic field at high latitudes during S2006 (a) and S2015 (d). The absorption plots for S2006 have been taken from [Zolotukhina et al., 2012]; for S2015, from the website [http://geophys.aari.ru/real_rio_arc.htm]. Here $H$ is the geomagnetic field component directed to the magnetic pole. The $H$ values for 2006 are available on the website [http://stdb2.stelab.nagoya-u.ac.jp/mm210]; for 2015, on the website [http://cdaweb.gsfc.nasa.gov/cdaweb/istp_public] 
Such a shift leads to an underestimation of auroral activity ( $A E$ index) and an overestimation of planetary activity ( $K_{\mathrm{p}}$ index) [Kamide, Maltsev, 2007; Levitin et al., 2012]. In Figure 1, $a$, the shift of jets relative to the standard $A E$ zone shows up as dissimilarity between $A E$ and $P C N$ variations and as low $A E$ during the main phase of S2006.

Plots in Figure 6 indicate that before the sudden commencement of S2006 and S2015 the MIT bottom was located respectively to the south of Yakutsk station and between Zhigansk and Yakutsk stations. This explains the presence of sporadic layers over both the stations, as well as the abnormal conditions of HF radio wave propagation along the Magadan - Irkutsk and Norilsk - Irkutsk paths before the onsets of the storms. Basing on this, we believe that the different responses of the subauroral ionosphere to initial phases of the storms (see 2.4.1) are not due to the shift of auroral precipitation zone (during SSC it was already over the observation points) but due to the varying intensity of auroral particle fluxes inducing impact ionization during $P_{\mathrm{sw}}$ jumps. Section 1 has shown that the corpuscular energy of auroral particle sources (symmetric ring current and plasma sheet) was higher before S2006 than that before S2015. In S2006, the additional ionization was caused by solar protons [Tereshchenko et al., 2007; Zolotukhina et al., 2012]. The enhancement of precipitating particle fluxes was accompanied by an increase in absorption of cosmic radio emission (see Figure 6, a), which indicates an increase in the electron density in the D-region.

Section 2 indicates that the sharp drop in the electron density (negative disturbance) in the noon-dusk sector occurred only at the end of the first step of the S2015 main phase. Prölss et al. [1991] attribute this effect to the lowering of the MIT latitude. In Figure $6, b$, the beginning of the sharp drop in $f_{0} \mathrm{~F} 2$ at Yakutsk station (at 09:00 UT onDecember 20) is marked with a black arrow. It corresponds to the beginning of the deepest shift of MIT to middle latitudes. From the model developed by Zherebtsov et al. [1986] it follows that the disturbances associated with the lowering of the MIT latitude might have occurred at Zhigansk station until 10:00 UT, and at Yakutsk station until 12:00 UT. This corresponds to the time of observation of the effects described in Subsection 2.2. The absence of the sharp evening drop in $f_{\mathrm{o}} \mathrm{F} 2$ during the December 14-16, 2006 storm can be explained by the low initial latitude of MIT that was to the south of Yakutsk station before SSC.

Referring to the plots in Figure 6, $b, d$, the MIT shift occurred simultaneously with the shifts of the auroral oval and inner edge of the plasma sheet. At that time, Tiksi station observed bay-like decreases in the magnetic field $H$ component, which were accompanied by reometric absorption enhancements typical for substormlike events [Driatsky, 1974]. An exception is the highest absorption peak denoted in Figure $6, d$ by a gray rectangle. This peak, observed at Tiksi station at $~ 22: 00$ UT, coincides in time with the short-term decrease in the auroral oval latitude by $\sim 5^{\circ}$ (indicated in Figure $6, b$ by a gray arrow) and with synchronous peaks of $A E$,
$P C N$, and PCS indices, but it is unrelated to the marked change in the $H$ component (Figure $6, d$, bottom panel).

Let us discuss features of daytime and evening effects of ionospheric storms caused, as derived from [Prölss et al., 1991], by large-scale disturbances of the thermospheric wind, variations in the chemical composition of the atmosphere, and TIDs. It is known that the main cause of daytime positive and negative disturbances is the heating of the high-latitude atmosphere by electrojets and auroral particles. The heating generates thermospheric wind disturbances including the enhancement of its meridional component (cause of the positive daytime disturbance of $f_{\mathrm{o}} \mathrm{F} 2$ ), and a change in the thermosphere chemical composition, in particular a decrease in $[\mathrm{O}] /\left[\mathrm{N}_{2}\right]$ (cause of the negative daytime disturbances of $f_{\mathrm{o}} \mathrm{F} 2$ ) [Prölss,2006; Mendillo, 2006; Dmitriev et al.,2017]. During impulse heating there occur TIDs propagating from high latitudes toward the equator [Buonsanto, 1999 ]. Superposition of TIDs can manifest itself as a long-term large-scale increase in $f_{\mathrm{o}} \mathrm{F} 2$ [Prölss et al., 1991].

Geoeffectiveness of interplanetary drivers is usually determined from the Akasofu parameter [Akasofu, 1981]. Power of high-latitude sources of heating can be estimated from $A E$ [Baumjohann, Kamide, 1984 ] as well as from PCN and PCS [Chun et al.,2002]. Plots of Akasofu parameter variations during the two storms are shown in Figure 7, $a$; variations in the power of sources of high-latitude heating calculated from $A E, P C N, P C S$, in Figure 7,b-d respectively. The plots are constructed with hour resolution. Zero hour corresponds to the onset of each storm main phase.

It is seen that the mean powers of the interplanetary driver and high-latitude heating sources in the initial, main, and early recovery phases of S2015 were 1.5 and 3-2 times (by various estimates) lower than those during S2006. However, due to the difference in duration between the main and early recovery phases by the beginning of the late recovery phase, the magnetosphereionosphere system received 1.5 times more energy from the interplanetary medium in S2015 than in S2006. Comparing plots in Figure 7, $e$ and $f$, we can see that this did not lead to significant differences in estimates of the energy expended on heating the atmosphere during the storms considered.

In both the cases, the estimate of energy consumed to heat the atmosphere, which was derived from PCS, is approximately twice as high as similar estimates obtained from $A E$ and $P C N$. This corresponds to the well-known effect of the prevailing summer-winter thermospheric circulation, which leads to a strong expansion of the region of the intense meridional wind and the region of abnormal atmosphere composition the wind transfers to the winter hemisphere [Fuller-Rowell et al., 1997]. In the cases under study, this effect was most pronounced on December 21 , in the early recovery phase of the storm.

Figure 8, $a$ and $b$ presents black and white maps of latitude-longitude distribution of $[\mathrm{O}] /\left[\mathrm{N}_{2}\right]$ for December 21 and, for comparison, for 20, 2015. Color original maps are 

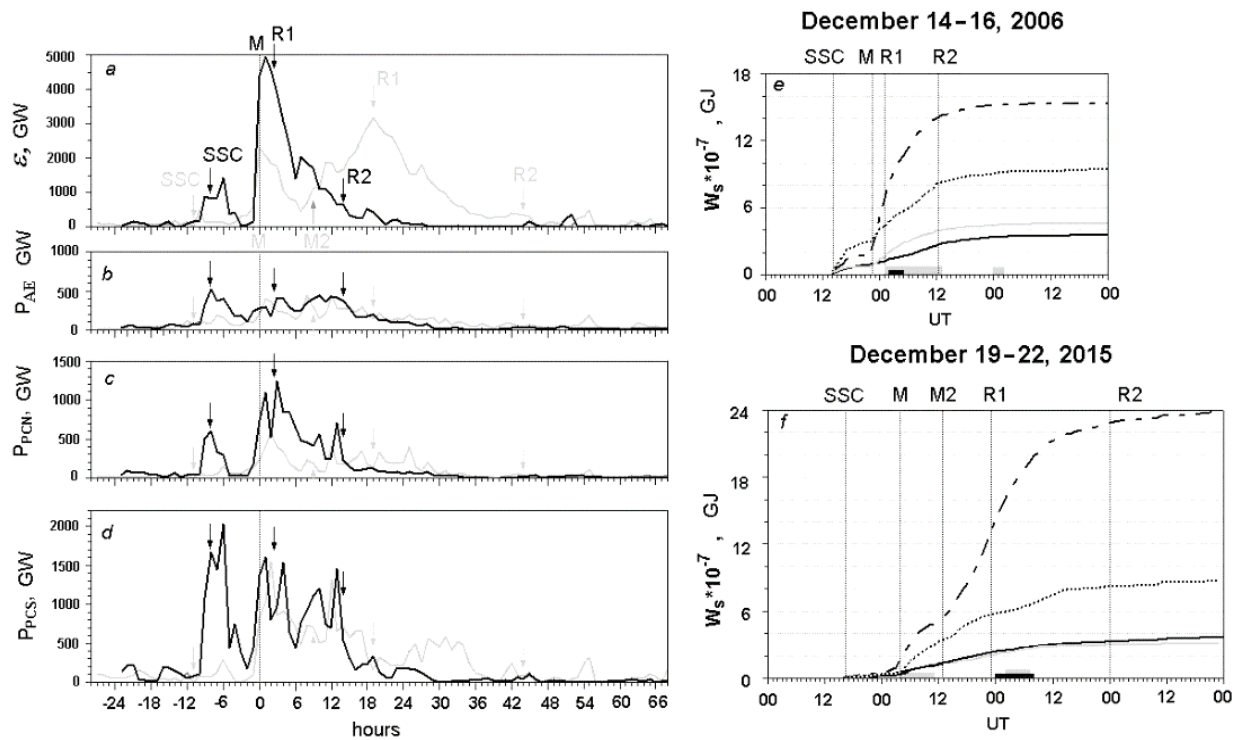

Figure 7. Variations in: Akasofu parameter $(\varepsilon)(a)$; power of heating of the high-latitude atmosphere calculated from $A E$ $\left(P_{A E}\right), P C N\left(P_{P C N}\right)$, and PCS ( $\left.P_{P C S}\right)$ indices $(b-d)$. Zero hour on the $\mathrm{x}$-axis corresponds to the beginning of the main phases of the storms. Black arrows mark the beginnings of phases of the December 14-16, 2006 storm; gray arrows, those of the December 19-22, 2015 storm. On panels $e$ and $f$ are plots of variations in the total energy $\left(W_{\mathrm{s}}\right)$ coming to the magnetosphere and expended on heating the atmosphere. The dash-dot, black, gray, and dashed lines indicate $W_{\mathrm{s}}$ variations, calculated from the Akasofu parameter, AE, PCN, and PCS indices respectively. Gray rectangles on the x-axis mark intervals of observation of positive ionospheric disturbances at Khabarovsk station; black ones, observation of negative ionospheric disturbances at Yakutsk station
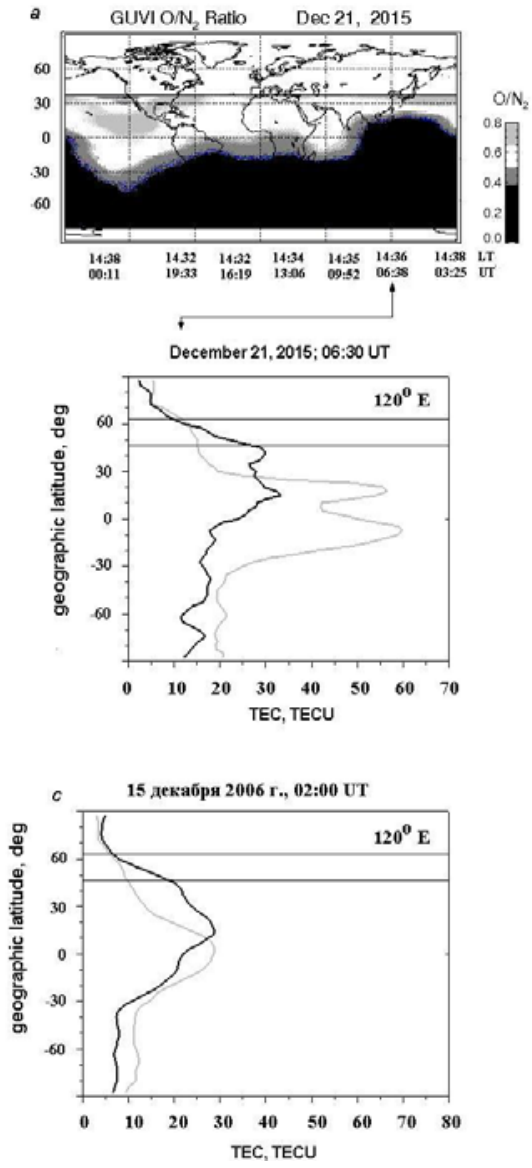
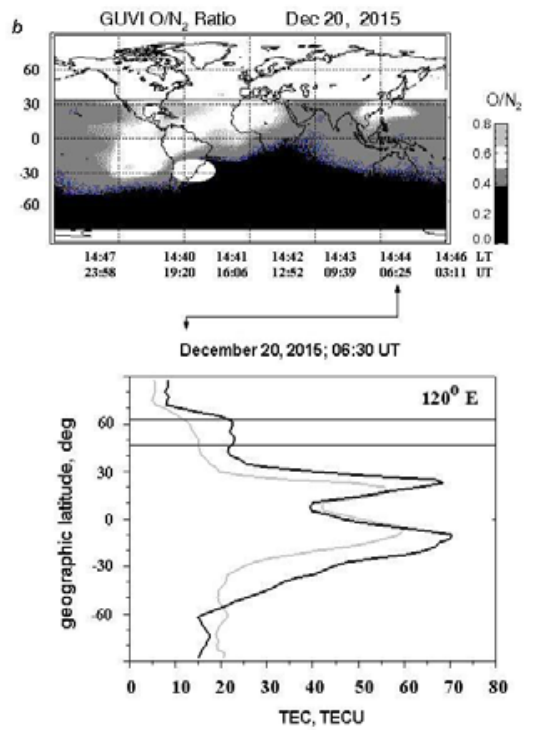

Figure 8. Black-and-white maps of $[\mathrm{O}] /\left[\mathrm{N}_{2}\right]$ distribution taken from the website [http://guvitimed.jhuapl.edu/guvigalleryl3on2] $(a, b)$, and TEC meridional profiles $(c, d)$ constructed for 06:30 UT of December 15 (gray lines), December 20 and 21 (black lines) close to the time of passage of the TIMED satellite along the meridian of $120^{\circ} \mathrm{E}$. Latitudinal distribution of TEC over the meridian of $120^{\circ} \mathrm{E}(\mathrm{e})$. Horizontal lines on the plots of TEC profiles indicate the latitudes of Yakutsk and Khabarovsk stations 
available on the website

[http://guvitimed.jhuapl.edu/guvi-galleryl3on2]. They show the [O]/[N2] distribution only in the latitude zone $-80-35^{\circ} \mathrm{N}$. Under the maps are plots ofTEC distribution (Figure 8, $c, d$ ) along the meridian of $120^{\circ} \mathrm{E}$ at 06:30 UT of the corresponding day. Referring to Figures 4 and $7, f$, we can see that in these moments the ionospheric stations located in East Asia observed positive ionospheric disturbances. Lines with arrows indicate that at 06:30 UT on December 20 and 21 the TIMED satellite, whose data are used to construct the maps, passed near the $120^{\circ}$ E meridian.

The map shown in Figure 8, a displays a transequatorial domain of low values of $[\mathrm{O}] /\left[\mathrm{N}_{2}\right]<0.4$. The meridional TEC profile corresponding to the map (Figure 8, c) is sharply asymmetric with respect to the equator. Comparing the maps and profiles of TEC shown in Figure $8, a-d$, we can see that for 24 hours the northern boundary of the domain of low $[\mathrm{O}] /\left[\mathrm{N}_{2}\right]$ along the meridian of $120^{\circ} \mathrm{E}$ shifted from $\sim 30^{\circ} \mathrm{S}$ to $\sim 15^{\circ} \mathrm{N}$, whereas the domain of low TEC values expanded from $\sim 60^{\circ} \mathrm{S}$ to $\sim 20^{\circ} \mathrm{N}$. During this period at $30-55^{\circ} \mathrm{N}$ there appeared a plateau-like area of increased TEC, and at high latitudes of the Northern Hemisphere, a region of relatively low TEC that was poorly resolved compared to the southern one and extended up to $\sim 60^{\circ} \mathrm{N}$. Note that during the daytime on December 20 all the stations in use recorded only positive ionospheric disturbances, which corresponds to the TEC profile in Figure 8, $d$ and indicates that the strong southward meridional wind made the major contribution to the generation of these disturbances. In contrast, the ionospheric disturbances developing during the daytime on December 21 occurred under the influence of at least two processes - the enhancement of southward and northward thermospheric winds and change in the atmospheric composition, which was most pronounced in the Southern Hemisphere. An additional factor that enhanced the north-south asymmetry of the ionospheric disturbances was the western orientation of the IMF azimuthal component. With such a direction of IMF $B_{y}$, the auroralelectrojets causing the Joule heating of the atmosphere are more intense in the Southern Hemisphere [Velichko et al., 2002].

We believe that the dominant influence of the atmosphere heating in the summer hemisphere on the development of ionospheric disturbances manifested itself also in the latitudinal TEC distribution illustrated in Figure 8, $e$ (02:00 UT for December 15, 2006). As derived from sounding data, at that time at high latitudes of the Northern Hemisphere, a negative ionospheric disturbance developed. The equatorial boundary of the disturbance was to the south of Yakutsk (see Subsection 2.3). In Figure 8, $e$, the low TEC values versus the background ones can, however, be seen only at -87.5$7.5^{\circ} \mathrm{N}$, i.e. in the Southern Hemisphere and in the vicinity of the equator. The poor quality of maps of the spatial distribution of $[\mathrm{O}] /\left[\mathrm{N}_{2}\right]$ for December 14-16, 2006 (available on the website only for the Southern Hemisphere) does not allow us to uniquely associate the domain of low TEC values with the region of the altered atmospheric composition.

Let us return to Figure 7, $e$ and $f$. The x-axes in these
Figures indicate the intervals of observation of positive and negative ionospheric disturbances at Yakutsk and Khabarovsk vertical sounding stations respectively. It can be seen that at the beginning of ionospheric disturbances on December 15, 2006 and December 21, 2015 the total energy received by the magnetosphereionosphere system since SSC exceeded $7 \cdot 10^{7}$ and $13 \cdot 10^{7} \mathrm{GJ}$ respectively. Recall that these disturbances developed against the TEC meridional distribution which was sharply asymmetric with respect to the equator. Comparing the values of the energy spent on heating the atmosphere, we can see that, according to three different estimates, 1.5 times less energy was expended on the heating by the beginning of the December 15, 2006 disturbances than that by the beginning of the December 21, 2015 disturbances.

In conclusion, we briefly discuss features of wavelike fluctuations of $f_{0} \mathrm{~F} 2$. In Subsection 2.3, we noted that Lei et al. [2008] using vertical sounding ionosonde data and results of model calculations have concluded that the wave-like ionospheric disturbances observed on December 15, 2006 were associated with TIDs excited at high latitudes of the Northern and Southern hemispheres. The detailed analysis of the experimental data used by Lei et al. [2008] has shown that there is no delay between the occurrences of the wave-like disturbances at spaced stations. The same result has been obtained from the analysis of wave disturbances observed on December 19-22, 2015. Furthermore, the 1.5-2 hr wave-like ionospheric disturbances occurred both before and during the storms and enhanced only in the vicinity of the dawn meridian.

\section{CONCLUSIONS}

The identified common features of ionospheric responses over East Asia to the December 14-16, 2006 and December 19-22, 2015 magnetic storms, which occurred during the same season, had similar hours of onset and intensity but differed significantly in duration of the main phases, are related to seasonal dynamics of ionospheric storms.

These differences between the ionospheric responses to the magnetic storms are associated primarily with the differences between pre-storm conditions of the magnetosphere-ionosphere system and durations of the main phases. The estimates of the energy brought by interplanetary drivers to the magnetosphere-ionosphere system during initial, main, and early recovery phases and the energy expended on heating the atmosphere have shown that the winter-summer asymmetry of the thermospheric circulation is one of the main factors determining the wind dynamics and affecting the generation and distribution of ionospheric disturbances. This defines the difference between the ionospheric responses to these ionospheric magnetic storms developed in the same seasonal conditions. During S2015, the wintersummer asymmetry of the ionospheric-thermospheric disturbances enhanced due to the intense Joule heating developing at high latitudes of the Southern Hemisphere at a negative azimuthal component of IMF. 
The work was carried out under the state task for 2018 from January 12, 2018 No. 007-00163-18-00 and was partially supported by RFBR grant No. 16-0500563. We have used experimental data obtained using the equipment of Center for Common Use "Angara" http://ckp-rf.ru/ckp/3056. We are grateful to the Yu.G. Shafer Institute of Cosmophysical Research and Aeronomy for providing magnetic and ionospheric data, to the Global Ionospheric Radio Observatory (GIRO), Russian Heliogeophysical Monitoring Center (RHMC), National Institute of Information and Communications Technology (NICT), and administration of the websites [http://ulcar.uml.edu/DIDBase;

http://wdc.nict.go.jp/IONO/HP2009/ISDJ/index-E.html] for providing vertical sounding data. We are indebted to NASA/GSFC's Space Physics Data Facility's [https://cdaweb.gsfc.nasa.gov/cdaweb/istp_public] for providing information on interplanetary magnetic field parameters and $S Y M-H$ index, as well as total electron content data obtained with Global Positioning System (GPS), the administration of the websites

[http://wdc.kugi.kyoto-u.ac.jp/wdc/Sec3.html] and [http://pc-index.org] for information on PCN, PCS, and $K_{\mathrm{p}}$ indices. We thank John Hopkins University Applied Physics Laboratory [http://guvitimed.jhuapl.edu] for providing data on $[\mathrm{O}] /\left[\mathrm{N}_{2}\right]$.

\section{REFERENCES}

Akasofu S.I. Energy coupling between the solar wind and the magnetosphere // Space Sci. Rev. 1981. V. 28. P. 121-190.

Bargatze L.F., Baker D.N., McPherron R.L., Hones E.V. Magnetospheric impulse response for many levels of geomagnetic activity. J. Geophys. Res. 1985, vol. 90, pp. 6387-6394. DOI: 10.1029/JA090iA07p06387.

Baumjohann W., Kamide Y. Hemispherical Joule heating and the $A E$ indices. J. Geophys. Res. 1984, vol. 89, pp. 383-388.

Borovsky J.E., Denton M.H. Solar wind turbulence and shear: A superposed-epoch analysis of corotating interaction regions at 1 AU. J. Geophys. Res. 2010, vol. 115, A10101. DOI: 10.1029/2009JA014966.

Borries C., Mahrous A.M., EllahounyN.M., Badeke R. Multiple ionospheric perturbations during the Saint Patrick's Day storm 2015 in the European-African sector. J. Geophys. Res.: Space Phys. 2016, vol. 121, pp. 11333-11345. DOI: 10.1002/ 2016JA023178.

Bryunelli B.E., Namgaladze A.A. Fizikaionosfery [Physics of the Ionosphere]. Moscow, Nauka Publ., 1988. 528 p. (In Russian).

Buonsanto M.J. Ionospheric storms - a review. Space Sci. Rev. 1999, vol. 88, pp. 563-601. DOI: 10.1023/A:1005 107532631

Chen Z., Wang J.-S., Huang C.-M., Huang L.-F. A new pair of indices to describe the relationship between ionospheric disturbances and geomagnetic activity. J. Geophys. Res.: Space Phys. 2014, vol. 119, pp. 10156-10163. DOI: 10.1002/ 2014JA020438.

Chun F.K., Knipp D.J., McHard M.G., Lacey J.R. Joule heating patterns as a function of polar cap index. J. Geophys. Res. 2002, vol. 107, no. A7, p. 1119. DOI: 10.1029/2001JA 000246 .

Clauer C.R., Cai X., Welling D., DeJong A., Henderson M.G. Characterizing the 18 April 2002 storm-time sawtooth events using ground magnetic data. J. Geophys. Res. 2006, vol. 111, A04S90. DOI: 10.1029/2005JA011099.

Dmitriev A.V.,Suvorova A.V., Klimenko M.V.,Klimenko V.V.,Ratovsky K.G.,Rakhmatulin R.A., Parkhomov V.A.
Predictable and unpredictable ionospheric disturbances during St. Patrick's Day magnetic storms of 2013 and 2015 and on 89 March 2008. J. Geophys. Res.: Space Phys. 2017, vol. 122, pp. 2398-2423. DOI: 10.1002/2016JA023260.

Driatsky V.M. Priroda anomal'nogo pogloshcheniya kosmicheskogo radioizlucheniya $v$ nizhnei ionosphere vysokik shirot [The Origin of Anomalous Absorption of Cosmic Radio Emission in the Lower Ionosphere at High-Latitudes]. Leningrad, Gidrometeoizdat, 1974. 224 p. (In Russian).

Ericsson S., Ergun R.E., Carlson C.W., Peria W. The cross-polar potential drop and its correlation to the solar wind. J. Geophys. Res. 2000, vol. 105, pp. 18639-18654.

Fuller-Rowell T.J., Codrescu M.V., Roble R.G., Richmond A.D. How does the thermosphere and ionosphere react to a geomagnetic storm? Magnetic Storms. Washington, 1997, pp. 203-226. (AGU Monograph. vol. 98). DOI: 10.1029/GM098.

Gonzalez W.D., Tsurutani B.T., Lepping R.P., Schwenn R. Interplanetary phenomena associated with very intense geomagnetic storms. J. Atmos. Solar-Terr. Phys. 2002, vol. 64, pp. 173-181.

Gonzalez W.D., Echer E., Tsurutani B.T., Clúa de Gonzalez A.L., Dal Lago A. Interplanetary origin of intense, superintense and extreme geomagnetic storms. Space Sci. Rev. 2011, vol. 158, pp. 69-89. DOI: 10.1007/s11214-010-9715-2.

Goodman J.M. Space Weather \& Telecommunications. New York, Springer, 2005, $382 \mathrm{p}$.

Huang C.M. Disturbance dynamo electric fields in response to geomagnetic storms occurring at different universal times. $J$. Geophys. Res. 2013, vol. 118, pp. 5149-5156. DOI: 10.1029/2012 JA018118.

Kalita B.R., Hazarika R., Kakoti G., Bhuyan P.K., Chakrabarty D., Seemala G.K., Wang K., Sharma S., Yokoyama T., Supnithi P., Komolmis T., YatiniC.Y., Le Huy M., Roy $\mathrm{P}$. Conjugate hemisphere ionospheric response to the St. Patrick's Day storms of 2013 and 2015 in the $100^{\circ} \mathrm{E}$ longitude sector. $J$. Geophys. Res.: Space Phys. 2016, vol. 121, pp. 11364-11390. DOI: 10.1002/ 2016JA023119.

Kamide Y., Winningham J.D. A statistical study of the "instantaneous" night side auroral oval: the equatorial boundary of electron precipitation as observed by the Isis- 1 and 2 satellites. J. Geophys. Res. 1977, vol. 82, pp. 5573-5585. DOI: 10.1029/JA082i035p05573.

Kamide Y., Maltsev Y.P. Geomagnetic storms. Handbook of the Solar-Terrestrial Environment.Berlin, Heidelberg, SpringerVerlag, 2007, pp. 355-374. DOI: 10.1007/11367758_14.

King J.H. Solar wind parameters and magnetospheric coupling studies. Solar Wind - Magnetospheric Coupling. Tokyo, Terra Scientific Publishing Company, 1986, pp. 163-177.

Lee D.-Y., Lyons L.R., Yumoto K. Sawtooth oscillations directly driven by solar wind dynamic pressure enhancements. $J$. Geophys. Res. 2004, vol. 109, A04202. DOI: 10.1029/2003 JA010246.

Lei J., Burns A.G., Tsugawa T., Wang W., Solomon S.C., Wiltberger M. Observations and simulations of quasiperiodic ionospheric oscillations and large-scale traveling ionospheric disturbances during the December 2006 geomagnetic storm. $J$. Geophys. Res. 2008, vol. 113, A06310. DOI: 10.1029/2008 JA013090.

Levitin A.E., Gromova L.I., Gromov S.V., Dremukhina L.A. $K_{\mathrm{p}}$-index and local high-latitudinal geomagnetic activity. Proc. the $9^{\text {th }}$ International Conference "Problems of Geocosmos". Saint-Petersburg, 2012, pp. 295-300.

Liu J., Wang W., Burns A., Yue X., Zhang S., Zhang Y., Huang C. Profiles of ionospheric storm-enhanced density during the 17 March 2015 great storm. J. Geophys. Res. 2016, vol. 121, pp. 727-744. DOI: 10.1002/2015JA021832.

Marmet P. New digital filter for the analysis of experimental data. Rev. Sci. Instrum. 1979, no. 50, pp. 79-83. 
Mendillo M. Storms in the ionosphere: patterns and processes for total electron content. Rev. Geophys. 2006, vol. 44, RG4001. DOI: 10.1029/2005RG000193.

Pirog O.M., Polekh N.M., Zherebtsov G.A., Smirnov V.F., Shi J., Wang X. Seasonal variations of the ionospheric effects of geomagnetic storms at different latitudes of East Asia. Adv. Space Res. 2006, vol. 37, pp. 1075-1080.

Prölss G.W., Brace L.H., Mayr H.G., Carignan G.R., Killeen T.L., Klobuchar J.A. Ionospheric storm effects at subauroral latitudes: a case study. J. Geophys. Res. 1991, vol. 96, no. A2, pp. 1275-1288.

Prölss G.W. Ionospheric F-region Storms: Unsolved Problems. Characterising the Ionosphere: Meeting Proceedings RTOMP-IST-056, Paper 10. Neuilly-sur-Seine, France: RTO, 2006, pp. 10-1-10-20. Available from:

http://www.rto.nato.int/abstracts.asp (accessed April 25, 2018).

Rodger A.S., Wrenn G.L., Rishbeth H. Geomagnetic storms in the Antarctic F-region. II. Physical interpretation. $J$. Atmos. Terr. Phys. 1989, vol. 51, pp. 851-866.

Romanova E.B., Tashchilin A.V. Modeling of structural features of electron density distribution in plasmasphere. Solnechno-zemnayafizika [Solar-Terr. Phys.]. 2013, vol. 22, pp. 21-23. (In Russian).

Sharma A.S., Baker D.N., Borovsky J.E. Nonequilibrium phenomena in the magnetosphere: phase transition, selforganized criticality and turbulence. Nonequilibrium Phenomena in Plasmas. Springer, 2005, pp. 3-22.

Tashchilin A.V., Romanova E.B. Modeling of plasmasphere properties under quiet and disturbed conditions. Geomagnetizmiaeronomiya [Geomagnetism and Aeronomy]. 2014, vol. 54, no. 1, pp. 13-22. (In Russian). DOI: 10.7868/ S0016794014010167.

Tereshchenko V.D., Vasiljev E.B., Ogloblina O.F., Tereshchenko V.A., Chernyakov S.M. The response of the polar lower ionosphere to powerful solar flares on December, 5-14, 2006. Physics of Auroral Phenomena: Proc. XXX Annual Seminar. Apatity, 2007, pp. 196-198.

Troshichev O.A., Kotikov A.L., Bolotinskaya B.D., Andrezen V.G. Influence of the IMF azimuthal component on magnetospheric substorm dynamics. J. Geomag. Geoelectr. 1986, vol. 38, pp. 1075-1088.

Troshichev O.A., Janzhura A.S., Stauning P. Unified PCN and PCS indices: method of calculation, physical sense and dependence on the IMF azimuthal and northward components. J. Geophys. Res. 2006, vol. 111, A05208. DOI: 10.1029/2005JA011402.

Tsurutani B.T., Gonzalez W.D. The interplanetary causes of magnetic storms: a review. Magnetic storms. Washington, 1997, pp. 77-89. (AGU Monograph. vol. 98). DOI: 10.1029/GM098.

Tsurutani B.T., Echer E., Shibata K., Verkhoglyadova O.P., Mannucci A.J., Gonzalez W.D., Pätzold M. The interplanetary causes of geomagnetic activity during the 7-17 March 2012 interval: a CAWSES II overview. J. Space Weather and Space Climate. 2014, vol. 4, A02. DOI: 10.1051/swsc/2013056.

Velichko V.A., Boroyev R.N., Gelberg M.G., Baishev D.G., Olson J.V., Morris R.J., Yumoto K. North-south asymmetry of the substorm intensity depending on the IMF $B_{y}$-component. Earth, Planets and Space. 2002, vol. 54, no. 10, pp. 955-961. DOI:10.1186/BF03352443.

Wang J.-S., Chen Z., Huang C.-M. A method to identify aperiodic disturbances in the ionosphere. Ann. Geophys. 2014, vol. 32, pp. 563-569. DOI: 10.5194/angeo-32-563-2014.

Yue C., Zong Q.G., Zhang H., Wang Y.F., Yuan C.J., Pu Z.Y., Fu S.Y., Lui A.T.Y., Yang B., Wang C.R. Geomagnetic activity triggered by interplanetary shocks. J. Geophys. Res. 2010, vol. 115, A00I05. DOI: 10.1029/2010JA015356.

Zhang S.-R., Zhang Y., Wang W., Verkhoglyadova O.P. Geospace system responses to the St. Patrick's Day storms in 2013 and 2015. J. Geophys. Res . 2017, vol. 122, pp. 69016906. DOI: 10.1002/2017JA024232.

Zherebtsov G.A., Pirog O.M., Razuvayev O.I. The high- latitude ionosphere structure and dynamics. Issledovaniyapogeomagnetizmu, aeronomiiifizikeSolntsa [Research on Geomanetism, Aeronomy and Solar Physics]. 1986, is. 76, pp. 165-177.

Zhou X., Tsurutani B.T. Interplanetary shock triggering of nightside geomagnetic activity: substorms, pseudobreakups, and quiescent events. J. Geophys. Res. 2001, vol. 106, pp. 18957-18967. DOI: 10.1029/2000JA003028.

Zolotukhina N., Polekh N., Kurkin V., Pirog O., Samsonov S., Moiseyev A.Magnetospheric disturbances associated with the 13 December 2006 solar flare and their ionospheric effects over North-East Asia. Adv. Space Res. 2012, vol. 49, pp. 883-897.

URL: https://cdaweb.gsfc.nasa.gov/cdaweb/istp_public (accessed November 11, 2016).

URL: http://wdc.kugi.kyoto-u.ac.jp/wdc/Sec3.html (accessed January 21, 2018).

URL: http://www.solen.info/solar/old_reports (accessed November 2, 2016). 2016).

URL: https://cdaw.gsfc.nasa.gov/CME_list (accessed May 31,

URL: http://sd-www.jhuapl.edu/Aurora/ovation/ovation_ display.html (accessed December 6, 2017).

URL: http://geophys.aari.ru/real_rio_arc.htm (accessed January 25, 2018).

URL: http://guvitimed.jhuapl.edu/guvi-galleryl3on2 (accessed April 12, 2018).

URL: http://ulcar.uml.edu/DIDBase (accessed April 12, 2018).

URL: http://wdc.nict.go.jp/IONO/HP2009/ISDJ/index-E.htr (accessed April 14, 2016).

URL: http://stdb2.stelab.nagoya-u.ac.jp/mm210 (accessed April 12, 2018).

URL: http://pc-index.org (accessed April 12, 2018).

URL: http://guvitimed.jhuapl.edu (accessed April 12, 2018).

How to cite this article

Zolotukhina N.A., Kurkin V.I., Polekh N.M. Ionospheric disturbances over East Asia during intense December magnetic storms of 2006 and 2015: similarities and differences. Solar-Terrestrial Physics. 2018. vol. 4, iss. 3, pp. 28-42. DOI: 10.12737/stp-43201805. 